\title{
Duplication 17q mosaicism: an infant with features of Ellis-van Creveld syndrome
}

\author{
ANDREA SEROTKIN, JUDITH STAMBERG, AND LEWIS WABER \\ Division of Human Genetics, Schneider Children's Hospital, Long Island Jewish Medical Center, New Hydę \\ Park, NY 11042, USA.
}

SUMMARY We describe an infant with multiple dysmorphic features who is mosaic for duplication $17 \mathrm{q} 21 \cdot 1 \rightarrow \mathrm{qter}$, owing to a direct tandem duplication. He is the first case with mosaicism for a $17 q$ duplication to be reported. His features are strikingly suggestive of Ellis-van Creveld syndrome.

Duplication $17 q$ is extremely rare and until recently no such cases had been reported. In the past few years about a dozen cases of partial duplication $17 q$ have been described and an identifiable syndrome is beginning to emerge.

We report a child with multiple anomalies who was found to be mosaic for duplication $17 \mathrm{q} 21 \cdot 1 \rightarrow$ qter but who lacked some features of this syndrome. Mosaicism for a tandem duplication of any chromosomal region is very unusual. Reasons for this are discussed.

\section{Case report}

The proband was the first child of healthy, unrelated parents. He was born at 42 weeks' gestation, after a normal term pregnancy, by caesarean section because of failure to progress. At the child's birth the father was 27 and the mother 26 years old. One previous pregnancy had resulted in a miscarriage at 12 weeks. The patient's birth weight and length were on the 25th centile and head circumference was on the 50th centile. He was referred for cytogenetic studies because of brachyrhizomelia of the extremities, micrognathia, bilateral simian creases, and generalised hypotonia. He had frontal bossing, bilateral ear pits, bilateral polydactyly of the feet,

Received for publication 14 April 1987. Accepted for publication 21 April 1987. and dysplastic nails. Also present were penileo chordee, bilateral inguinal hernias, a pectus excava의 tum, a supernumerary rib (right side), a deepanterior palate, and a lip tie. His gums had scallope edges and two neonatal teeth were evident. He appeared alert and active. Surgery was performed ato two months for correction of the chordee and the hernias. At this time the supernumerary toes were removed and circumcision was also performed. $A D$ seven months of age a developmental assessmen revealed delay in all areas. Cognitive skills were a the five month level and gross motor skills were ao the two to three month level. Slow growth wa\& apparent, with both length and weight well below $\overrightarrow{\mathscr{B}}$ the 5th centile. At one year growth parameters were on the 50th centile for five months for height and three months for weight.

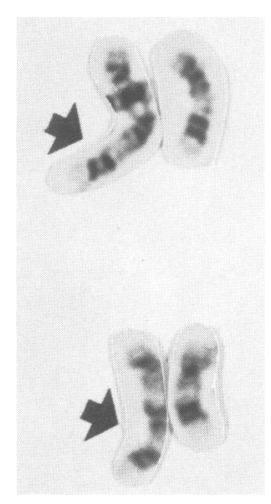

FIGURE $G$ banded partial karyotype from two cells of proband, showing chromosome 17 with the duplication (left) and normal chromosome 17 (right). Arrows indicat duplicated segment $q 21 \cdot 1 \rightarrow q$ ter attached to terminus. 


\section{CYTOGENETIC STUDIES}

Chromosome analysis was performed on peripheral blood lymphocytes and on fibroblast cultures established from foreskin and a supernumerary toe. Standard cytogenetic techniques were used including trypsin-Giemsa banding. Analysis of the blood revealed extra chromosomal material attached to the terminus of one chromosome 17 in 36 of 70 cells examined $(50 \%)$. The remaining cells had a normal male karyotype. The extra segment was identified as a tandem direct duplication of the distal two-thirds of the long arm of chromosome 17 (figure). The karyotype is described as $46, \mathrm{XY} / 46, \mathrm{XY}$, dir dup(17) (pter $\rightarrow$ q25::q21·1 $\rightarrow$ qter). The foreskin cultures showed the abnormal chromosome 17 in all 54 cells analysed. Cells from a culture established from one of the supernumerary toes showed a mosaic pattern, with 60 of 92 cells abnormal $(67 \%)$. The parents were not willing to have their chromosomes studied.

\section{Discussion}

Duplications of $17 q$ are extremely rare. This is only the thirteenth reported case. Nine of these were the result of a parental translocation inherited in unbalanced form and only four were apparently the result of a de novo event. Naccache et al and Bridge $e t a l^{2}$ have summarised the clinical features in patients with duplication distal 17q. A distinct clinical syndrome has been proposed in which the major features are: profound mental retardation, dwarfism or severe growth retardation, psychomotor delay, frontal bossing and temporal retraction, microcephaly, large mouth with thin lips and downturned corners, cleft or highly arched palate, micrognathia, low set malformed ears, short and/or webbed neck, rhizomelia of the extremities, and polydactyly. The region $17 \mathrm{q} 23 \rightarrow$ qter appears to be the segment correlated with this syndrome. ${ }^{1}$

Our patient, who is mosaic for duplication $17 q 21 \cdot 1 \rightarrow$ qter, has a phenotype largely consistent with this picture, although the conspicuous craniofacial dysmorphism is absent. This is surprising considering that our patient has the segment thought to be critical, plus additional duplicated material. Indeed, his duplication corresponds to that of the patient of Gallien $e t a l^{3}$ whose manifestations were so severe that she died immediately after birth. It may be that the abnormalities in our patient are less severe due to the absence of any monosomy and to the mitigating effect of the normal cell line.

We note that our patient is only the fourth in whom the phenotypic effect of a duplication for part of $17 q$ is not complicated by the effect of monosomy for part of another chromosome. Orye and van Bever ${ }^{4}$ reported a patient who, like ours, had partial trisomy 17 owing to a de novo tandem duplication. The patients reported by Fryns $e t a l^{5}$ and Parcheta $e t$ $a l^{6}$ had partial trisomy 17 resulting from apparently de novo translocations involving the short arms of chromosomes 21 and 14, respectively. Since the short arms of these chromosomes are polymorphic regions where variability in size or total absence has no effect on the phenotype, ${ }^{7}$ the characteristics of these patients are also attributable purely to the duplication of part of chromosome 17. The lack of a consistent phenotype may be due to the different regions of chromosome 17 included in these duplications. Furthermore, identification of additional material on a chromosome by cytogenetic techniques alone is often difficult when the extra material cannot be traced to a parental balanced translocation. The smaller the length of extra material, the more difficult becomes the problem of identification. In cases where the segment is large, and extended banding techniques are applied, the identification of the segment as a part of chromosome 17 is more reliable.

Our patient's phenotype showed a remarkable resemblance to Ellis-van Creveld syndrome, although there is no consanguinity, no family history of that disorder, and the family is not of Amish descent. Rhizomelic limbs, bilateral polydactyly, dysplastic nails, and natal teeth are frequently encountered in Ellis-van Creveld patients, although in that disorder polydactyly of the hands is more common than polydactyly of the feet. Also not consistent with Ellis-van Creveld syndrome is developmental delay. However, chromosome study may prove useful in other apparently atypical cases of Ellis-van Creveld syndrome.

Our patient represents the first reported case of mosaicism for a duplication involving chromosome 17 , and only the sixth reported case of mosaicism for a tandem duplication of any chromosome. ${ }^{8}$ This implies that duplications are more likely to occur as errors in meiosis than in mitosis. Inverted duplications can arise as the result of crossing over within an inversion loop at meiosis in a paracentric inversion heterozygote. ${ }^{9}$ Other mechanisms involving errors at crossing over have also been suggested. ${ }^{10}$ It has been speculated that direct duplications can arise as the result of unequal crossing over. ${ }^{11} 12$ Because both types of duplications arise through crossing over, which occurs regularly at meiosis but rarely at mitosis, it is therefore not surprising that mosaic duplications are so rare.

\footnotetext{
References

1 Naccache NF, Vianna-Morgante AM, Richieri-Costa A. Duplication of distal 17q: report of an observation. Am J Med Genet 1984;17:633-9.
} 
2 Bridge J, Sanger W, Mosher G, et al. Partial duplication of distal 17q. Am J Med Genet 1985;22:229-35.

${ }^{3}$ Gallien JU, Neu RL, Wynn RJ, Steinberg-Warren N, Bannerman RM. An infant with duplication of $17 \mathrm{q} 21 \rightarrow 17 \mathrm{qter} . A m J$ Med Genet 1981:8:111-5.

+ Orye E, Van Bever H. De novo distal trisomy 17q. Ann Genet (Paris) 1985:28:61-2.

Fryns JP, Parloir C, Van den Berghe H. Partial trisomy $17 \mathrm{q}$. Karyotype 46,XY,der[21],t[17;21][q22;p13]. Hum Genet 1979; 49:361-4.

- Parcheta B, Skawinski W. Wisnicwski L. Piontek E. Gutkowska A. Wermenski K. A new case of partial trisomy of 17 long arm Densitometric analysis of aberrations. Eur J Pediatr 1985;143: 314-6.

7 Therman E. Human chromosomes. New York: Springer-Verlag, 1986:211-3

* Schwartz S, Schwartz MF, Panny SR, Peterson CJ, Waters E, Cohen MM. Inherited X-chromosome inverted tandem duplication in a male traced to a grandparental mitotic error. Am J Hum Genet 1986;38:741-50.
" Mules EH. Stamberg J. Reproductive outcomes of paracentric $\stackrel{\mathbb{D}}{\text { ! }}$ inversion carriers: report of a liveborn dicentric recombinan $\vec{G}$ and literature review. Hum Genet 1984:67:126-31.

11) Taylor KM, Franke U, Brown MG, George DL, Kaufhold MT Inverted tandem ["mirror"] duplications in human chromosomes: inv dup 8p, 4q, 22q. Am J Med Genet 1977:1:3-19.

"Vogel W, Back E, Imm W. Serial duplication of 10[q11 $\rightarrow$ q22] in? a patient with minor congenital malformations. Clin Gene 1978:13:159-63.

12 Van Dyke DL, Miller MJ, Weiss L. The origin of inverted tandem duplications, and phenotypic effects of tandem duplication of the X-chromosome long arm. Am J Med Genet 1983:15:441-50.

Correspondence and requests for reprints to Dr Stamberg, Division of Human Genetics, Schneideriu Children's Hospital, Long Island Jewish Medicals Center, New Hyde Park, NY 11042, USA.

\title{
De novo partial trisomy $15 \mathrm{q}$ (proximal type)
}

\author{
T J HERWEIJER*, J W E OORTHUYS* $\dagger$, AND N J LESCHOT $\dagger$ \\ * Department of Pediatrics, and †Department of Human Genetics, Academic Medical Center, University of \\ Amsterdam, Meibergdreef 9, 1105 AZ Amsterdam, The Netherlands.
}

SUMMARY This report describes a retarded girl with strabismus, high arched palate, antimongoloid slant, low set ears, hearing loss, micrognathia, short neck, and an anteriorly displaced anus. She was found to have a de novo partial trisomy of the proximal part of the long arm of chromosome 15.

De novo partial trisomy of the proximal part of the long arm of chromosome 15 has been described in nine patients. ${ }^{1-8}$ We present the clinical and cytogenetic findings in an infant with partial trisomy of the proximal part of the long arm of chromosome 15.

\section{Case report}

The proband was the first child of healthy young parents. Delivery was induced at 42 weeks after a normal pregnancy. Birth weight was $2800 \mathrm{~g}$ and length $47 \mathrm{~cm}$. Directly after birth the child showed typical dysmorphic signs, such as a broad nose with a bifid tip, narrow nostrils, telecanthus, blepharophimosis, bilateral absence of the middle phalanx of the fifth finger, abnormal palmar creases, and an anteriorly displaced anus. Respiratory distress

Received for publication 23 March 1987

Revised version accepted for publication 1 April 1987. required oxygen and extra suction of the respiratory tract. Respiration was impaired and a nasal stridor $\bar{\Phi}$ was present. A blood sample was taken for chromosome analysis. She was discharged at the age of two 응 weeks.

In the first months frequent upper respiratory tract infections caused adenohypertrophy. In spite of adenotomy, the girl was admitted to hospital several times elsewhere because of decompensatio ${ }_{0}^{\circ}$ cordis. At the age of eight months she was seen by a 3 . cardiologist and echocardiography revealed right $\delta$ ventricular hypertrophy but no primary cardiac 3 abnormality. The right ventricular hypertrophy was 0 thought to be caused by recurrent respiratory tract infections.

These infections and the narrow nostrils, as well as tube feeding, contributed to upper airwayor obstruction.

At the age of 15 months she was admitted to ourN hospital for another adenotomy and uvulectomy. $\omega$ Examination showed a cyanotic, dyspnoeic infant with impaired inspiration. Length was $68 \mathrm{~cm}$ (below the 3rd centile), weight $6590 \mathrm{~g}$, and head circumference $45 \mathrm{~cm}$ (15th centile). The head was symmetrical. In addition to the findings at birth (tele-o canthus and blepharophimosis), the eyes showed aब strabismus convergens, bilateral ptosis, slight antimongoloid slant, and inverse epicanthus (fig 1).을 There was hypoplasia of the peripheral frontal parte 